\title{
Creativity and Logical-Spatial Skills in Blind and Visual Impaired Adolescents. First Results of the FIRD Project
}

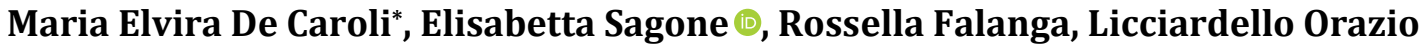 \\ Department of Educational Sciences, University of Catania, Catania, Italy \\ Email: ${ }^{\star}$ m.decaroli@unict.it
}

How to cite this paper: De Caroli, M. E., Sagone, E., Falanga, R., \& Orazio, L. (2020). Creativity and Logical-Spatial Skills in Blind and Visual Impaired Adolescents. First Results of the FIRD Project. Psychology, 11, 404-418.

https://doi.org/10.4236/psych.2020.113026

Received: February 6, 2020

Accepted: March 13, 2020

Published: March 16, 2020

Copyright () 2020 by author(s) and Scientific Research Publishing Inc. This work is licensed under the Creative Commons Attribution International License (CC BY 4.0).

http://creativecommons.org/licenses/by/4.0/

\begin{abstract}
This study reported the first results of the FIRD Project about the haptic versions of the Test of Divergent Thinking and of the Colored Progressive Matrices for blind and visually impaired participants. Performance reached by three male adolescents, one born blind, one visually impaired from birth, and one born sighted and then become blind were analyzed. High levels of difficulty were mostly noted in the born blind adolescent both in relation to creative abilities and logical-spatial skills, while good performance was obtained by adolescent who became blind.
\end{abstract}

\section{Keywords}

Creativity, Logical-Spatial Skills, Blind and Visual Impaired Adolescents, FIRD Project

\section{Introduction}

For many years now scholars agree on the importance of creativity which, in a world in which resources are increasingly being reduced, seems to be the only theoretically infinite resource that humanity will have at its disposal to solve the ever more complex problems that characterize our current existence. The central relevance of divergent ability, demonstrated by the many scientific discoveries that took place through serendipity (Mednick, 1962), has made it necessary to understand the nature of this process which has often assumed very different meanings on the basis of the various theoretical models. The model that provides more articulated answers and measures seems to be the factorial one. In this perspective, creative thinking is made up of specific and equally important factors useful for achieving functional solutions especially in situations characte- 
rized by problem-solving. The divergent production, defined by Guilford (1982) in the famous Three-Dimensional Model of the Intellect, is characterized very differently with respect to the convergent production, which functioning is exemplified by the tendency to reach a solution considered as unique, supported by logical reasoning, based on the use of known and already used strategies (De Caroli, 2009). The divergent production, on the other hand, tends to search for a greater number of solutions, restructuring the situation through new conceptual trials. The factors that constitute divergent production are the ideational fluidity, that is the ability to produce a large number of ideas starting from a verbal, graphic or conceptual stimulus; the ideational flexibility, or the ability to change mental settings, moving from one category to another different from the previous one, and to break away from a succession of ideas to easily move on to other "creative chains"; the originality, that is the ability to produce rare and unusual responses to which a reduced number of individuals think (Guilford, 1950; Runco, 1991). A later addition to these factors is the elaboration, named as the ability to enrich, with sensible details, the ideas produced by the individual, combining the elements that constitute the conceptual structures called into question in an original way. These factors, which bring forth cognitive abilities functional to the solution of the problems, quite clearly appear to be very useful to the able-bodied individuals; thus, they are clearly important to those who do not fully possess the usual sensory/perceptive skills for facing and successfully overcoming the difficulties present in everyday reality. We are referring to blind and visually impaired individuals whose divergent abilities, as well as logical-spatial ones, can be negatively or positively affected by their specific visual condition (see Halpin, Halpin, \& Torrance, 1973; Eardley \& Pring, 2007).

The analysis of the scientific literature has shown the presence, also in our context, of research aimed to verify the levels of creativity in atypical developed populations (e.g., children with intellectual disabilities: De Caroli \& Sagone, 2010; children with Down syndrome: De Caroli \& Sagone, 2014). We weren't able to find studies on creativity expressed by blind and visually impaired individuals by means of haptic tests, but only with the use of verbal tests. In addition, Tisdall, Blackhurst, and Marks (1971) found that blind children were more verbally fluent than seeing ones, even if blind children and seeing ones did not generally differ in the ability to think divergently. Thus, Halpin and colleagues (1973) found that blind children were more fluent, flexible, and original than sighted ones using verbal tasks of the Torrance Test of Creative Thinking. In addition, Wyver and Markham (1999) noted similar scores between children with severe visual impairments and sighted ones in the Alternate Uses Test. These interesting but outdated results have a very serious limit on the exclusive use of verbal tests. In visual disabilities, the mediation of haptic perception is fundamental in encouraging contact with reality; so, some studies have demonstrated the usefulness of haptic-type tools for verifying the presence of ToM (Theory of Mind) in blind children that showed a great delay in the perspective taking measured by testing 
first-order false-beliefs tasks and concluded by assuming that, comparable to autistic individuals, these difficulties were attributable to limits in the acquisition of the antecedents of ToM (see McAlpine \& Moore, 1995; Minter, Hobson, \& Bishop, 1998; Green, Pring, \& Swettenham, 2004). Brambring and Asbrock (2010) used alternative false-belief-tasks based on tactile and auditory experiences with congenitally blind children, finding a small delay of about two years in blind children compared to the sighted ones. More recently, in the task related to the unexpected objects, Pijnacker and colleagues (2012) used objects that could be recognized through the touch and in which the importance of vision was minimal, reporting that "children with a variety of congenital visual impairments have no developmental delay in more advance theory of mind understanding" (p. 2449). It is evident that the haptic modality represents the main tool, alternative to the visual ability, for the recognition modality and perceptive-cognitive development of blind individuals (see Withagen, Verloed, Janssen, Knoors, \& Verhoeven, 2010; Occelli, Lacey, Stephens, John, \& Sathian, 2016), above all because it makes possible to understand the relationships between space and form, allowing for a rich transmission of information. Through the haptic aids, the analysis of the levels reached in the logical-spatial skills, evidently compromised by visual disability, is traceable only in an interesting instrumental validation reported by Rich (1963) who made a tactile version of the Raven Matrices constructed of balsa wood, cardboard, and wire, starting from a previous empirical study realized by Anderson (1961) with blind adults using the Tactual Progressive Matrices (TPM). With these tools, Rich (1963) verified the correlation between the scores obtained by administering the Raven Matrices and the WISC verbal subscales, discovering that "a substantial relationship existed between the two tests" (p. 48), overall in 12 to 15 year old group. It is important to remember that the Raven tests investigate the "matrices", that is the ways of elaboration of specific visual-spatial data or information, correlated among them by different rules or organizational modalities: perceptive and spatially oriented. The choice to use this specific test with visually impaired participants derived from the type of skills that individuals must use to carry out the tests. These abilities, which can be reduced by the specific disability, are fundamental for the functional adaptation of the individual and for overcoming problematic situations.

\section{Method}

\subsection{Purpose of the FIRD Project}

Considering the importance of divergent thinking and logical-spatial abilities, especially in reference to blind and visually impaired individuals, we have conceived a project (FIRD Project, University of Catania) with the following objectives over the years:

1) To realize/produce the Williams' Test of Divergent Thinking (TDT) and Raven's Colored Progressive Matrices in order to make possible the haptic perception (first step discussed in this paper); 
2) To administer these instruments to blind and visually impaired adolescents (second step discussed in this paper);

3) To strengthen the inadequate divergent skills in blind and visually impaired adolescents through specific individual laboratory activities (third step to realize in the subsequent period);

4) To follow up by administering the parallel form of the TDT to see if and to what extent the actions produced have enhanced creative abilities (that is, final step to develop in the last period of research).

\subsection{Participants}

From October 2018 to August 2019 we collected the data of the blind and visually impaired participants who adhered to our request to participate in this project, also with the collaboration of the President of the Catania Territorial Section of the Italian Union of the Blind and Visually Impaired. The general socio-demographic information indicated the absence of other disabilities and the exclusive presence of blindness or reduction of vision. These information was obtained by the official of the Institution. All relevant details of the study were provided by researchers and parents were asked to give their informed consent in accordance with art.13 of the Italian Legislative Decree 196/2003 for data privacy (Code Regulating Personal Data Protection). Researchers followed the Ethical Code for Italian psychologists (L. 18.02.1989, n. 56) and the Ethical Code for Psychological Research (reviewed in March 27, 2015) by Italian Psychologists Association. In this paper we have decided to present the data referring to the following three adolescents:

- F., 16 yrs, boy visually impaired from birth, attends to the Catania Territorial Section of the Italian Union of the Blind and Visually Impaired (UICI) since 2009 and performs postural activities (functional gymnastics to improve the perception of the bodily self). At the time of the administration of the tests, he was enrolled in the second year of the social-psycho-pedagogical High School. His father and mother are both employed.

- M., 14 yrs, sighted born boy, became progressively visually impaired and then totally blind. He is member of the Catania Territorial Section of the Italian Union of the Blind and Visually Impaired (UICI) since 2011. He studies Braille and English. He carries out postural activities. At the time of the administration of the tests, he was enrolled in the first year of the Technical High School. His father and mother are both employed.

- N., 14 yrs, blind boy from birth, is member of the Catania Territorial Section of the Italian Union of the Blind and Visually Impaired (UICI) since 2007. He studies Braille and English and carries out postural activities. His father is employed and his mother is a housewife.

All three subjects attend to computer courses delivered by the Institution, using a computer with a keyboard and a monitor suitable for the specific disability and summer stages activated by the Italian Union of the Blind. Among all the 
people we analyzed, we have chosen the three aforementioned because they have common characteristics: they are adolescents, belonging to the Secondary Education, their parents belong to a similar social class, they attend the same functional activities to improve their body perception. In the face of this similarity, the three adolescents differ only in relation to the visual impairment that we could consider as independent variable. This choice can allow us to understand how much the experience of visual perception and the severity of the visual impairment can affect creative performance produced by the three adolescents.

\subsection{Measures and Procedure}

In reference to the first step, as reported in De Caroli and colleagues' research (2019), we asked for the collaboration of the Regional Braille Stamperia of Catania. Thus, in the first year of the project, we have faced the issue of realize the tools for assessing creative skills and logical-spatial and problem solving skills, in collaboration with the Regional Braille Stamperia of Catania which deals with typhloid-learning aids. After numerous meetings with specialists and typhlologists working at the Braille Stamperia, the enlarged versions of the Test of Divergent Thinking (protocol A and B; see Williams, 1994) to be used with the visually impaired participants and those with raised stimuli for the blind ones were produced.

TDT-The Test of Divergent Thinking is formed by 12 frames containing incomplete graphic stimuli shown to children, who were then asked to draw a picture; it is possible to evaluate the following five scores: fluency, flexibility, originality, elaboration, and production of titles. The fluency score was the total number of significant and meaningful pictures created by participants (range 1 12 points). The flexibility score was the number of changes of ideas from one category to a different one (range $1-11$ points). The originality score was the total number of pictures drawn inside or outside each incomplete stimulus placed in the frames (range 1 - 36 points); one point was assigned to each picture drawn outside the stimuli, two points to each picture drawn inside the stimuli, and three points to each picture drawn both inside and outside the incomplete stimuli. The elaboration score was the number of asymmetric pictures drawn by children (range 1 - 36 points): zero points were assigned to the symmetrical pictures, one point to the asymmetric pictures drawn outside the incomplete stimuli, two points to the asymmetric pictures inside the incomplete stimuli, and three points to the asymmetric pictures drawn both inside and outside the stimuli. Finally, the score of the production of titles was the sum of points assigned to each title produced by children: one point was assigned for simple titles, two points for titles with qualifying and descriptive adjectives, three points for imaginative titles indicating something beyond the picture drawn by participants (range 1 36 points).

In order to adapt these measures to visually impaired participants, the Braille Stamperia arranged a variant by enlarging the graphic signs that act as a stimulus 
(A3 sheet folded according to the orientation of the test), present in the 12 frames provided by the test and in the raised version for the blind participant by printing on thermoformed A4 sheets with 2 frames for each sheet. Through the use of the awl, the blind can perform the test. The raised version was specifically created to make possible for these participants to have the "haptic perception" of the stimuli coming from the combination of tactile perception with the position of the hand with respect to the stimulus. As reported by Kirby and D'Angiulli (2011: p. 69), "the neurological overlapping of visual and haptic processing seems to indicate that the haptic system may be able to recruit the object representation systems of the ventral visual pathway" (see Vanlierde, De Volder, Wanet-Defalque, \& Veraart, 2003; Pietrini, Furey, Ricciardi, Gobbini, Wu, et al., 2004), an effect observed in previous studies investigating the neurological processes of visually impaired individuals.

The realization of these versions of the TDT can make the use of this test accessible to the visually impaired and blind individuals and will allow them to express their divergent abilities up to now not verifiable with the existing psychometric tools. We have arranged these two versions of the Williams' TDT in order to be able to achieve the last step of this project. So, once we have assessed the level of creativity reached by blind and visually impaired participants using protocol A, we will offer them functional training program to enhance divergent thinking (see Al-Dababneh, al-Masadeh, \& Oliemat, 2015; De Caroli, Falanga, Licciardello, \& Sagone, 2017). The eventual changes will be made using the protocol B of the Williams' TDT. These protocols are entirely comparable and are both constituted by 12 frames containing incomplete graphic stimuli (different for $\mathrm{A}$ and $\mathrm{B})$.

CPM-Together with the TDT, the Raven's Progressive Matrices (standard SPM and colored CPM) were created in both versions, with raised stimuli for the blind and with enlarged stimuli for the visually impaired participants. In all the versions of the Raven's Matrices, the following psychological dimensions are required and involved: a) perceptive discrimination of a visual-spatial type; b) analogical reasoning (to connect and establish relationships on the basis of form, texture, orientation and other perceptive evidence); c) evaluation of the alternatives of response and exclusion, on a perceptive/logical basis, of the negative (wrong) ones; d) ability to establish relationships between different information in order to choose the right elements; e) focused attention; f) sustained attention; g) working memory (to keep in mind the data present, putting them at the same time in correlation, comparing them to reach the solution); h) ability to learn a working method (by going forward in the test the subject should acquire a working method that allows him to improve performance); i) learning ability (passing from one item to another of the same series the subject should learn to extend the previously learned rules to subsequent tests). In the Raven's Colored Matrices version the following skills are involved: a) ability to identify the analogy; b) identity recognition based on individual or joint criteria of form, color, size, 
quantity, direction; c) orientation, figure/background, density; d) ability to grasp symmetry; e) identification of corresponding and/or complementary elements with respect to an "organized whole" according to gestalt-type configurations; f) ability for logical-deductive thinking (a reasoning that starts from the general rule to get to the particular); g) discovery of abstract and formal relationships according to an operative-deductive logic. Operationally, these matrices are booklets in the standard form consisting of 5 series (A, B, C, D, E) of 12 items each and in the colored form consisting of 3 series $(\mathrm{A}, \mathrm{Ab}, \mathrm{B})$ of 12 items each, with a print with raised stimuli in the $20 \times 25 \mathrm{~cm}$ format for the blind and an enlarged print in the $29 \times 36 \mathrm{~cm}$ format for the visually impaired participants, with binding in plastic backs containing the matrices in four-color/monochrome. These matrices provide for the identification of the correct option among the 6 or 8 alternatives present in the sheet that completes the proposed matrix as a stimulus; the haptic and enlarged version will allow us to measure the logical-spatial abilities and the fluid intelligence of blind and visually impaired participants. As reported by Muniz and colleagues (2016: p. 260), the colours are irrelevant to solving the problems; therefore, this version can also be used for blind individuals. In addition, the Colored Matrices were conceived, as indicated by the inventor (Raven \& Court, 1998), for children (5 - 11 years) and elderly people also with clinical problems. In the last Italian standardization (Belacchi et al., 2008), the subjects were aged between 3 and 11. We have decided to use the Colored Matrices for all the participants, even those over the age of 11, for two reasons. The first concerns the fact that most of the participants we take into consideration fall into this age group. The maximum age difference does not exceed five years. The second reason regards the absolute absence of comparisons and indications inferable from the literature that has prompted us to start research using a simpler tool from which to draw successive indications about the usability of the forms more complex.

About the procedure of administration of tools, these subjects were greeted by two investigators who accompanied them to a room of the above mentioned office. We have decided to use the same researchers in order to avoid possible interferences in the way of administration also connected to the tone, the inflections of the voice, etc., therefore ensuring as much as possible the uniformity of the set. Participants were told that their moms would wait for them in a nearby room. This request was functional to avoid verbal interferences from the mothers. The choice of location was motivated by the fact that all the participants were regular visitors to the site, which is therefore a well-known place in which they usually move without difficulty and without anxiety. Once the subject had settled down, the researcher left the room and explained to the parents the aims of the research, the type of activities that the child would carry out and the time that, on average, he/she would use. Once this procedure had been carried out, the researcher explained to the participants that they would soon start a pleasant activity together, for which, he/she had to concentrate and pay close attention. 
Once the consent was obtained, the researcher proceeded with the administration of the Williams' TDT, asking the subject to search the signs raised for as long as necessary, until they were clear. We have devoted a lot of attention to this initial phase because the haptic perception depends on the information that comes from the contact, the active production of movements, and familiarity (Millar, 1994). While one researcher administered the tests, the other one registered the answers and the response times. After completing this activity the researcher asked the subjects if they were tired, if they wanted to take a break or to continue with a different activity. All interviewees stated that they were not tired and that they wanted to continue the activity. The researcher then proceeded to administer the Raven's Colored Progressive Matrices.

\section{Results}

Creative performance. We reported the results obtained by each participant with the application of Test of Divergent Thinking compared to the normative scores (Table 1). So, it emerged that the performance expressed by N., boy blind from birth, carried out in 20 minutes and using the awl, was very widely "below average" in all creativity factors. In detail, the six completed frames contained two geometrical figures, one the tile (also a square), two the clock, one a wall (a rectangle). The results achieved by the other two participants were different; so, in relation to fluidity, flexibility, and originality, the performances of $\mathbf{M}$. and $\mathbf{F}$. were on average, while for elaboration, production of titles, and total scores were equal to "below average". A more careful observation seemed to indicate that the results of M., boy born sighted and then become blind, differed from the "below average" score much less than for F., who is a visually impaired boy from birth. This means that $\mathbf{M}$. shared an excellent ability compared with $\mathbf{F}$. in relation to the quantity of graphic achievements (fluidity) and on average adequate in being able to create a design outside and inside the closed form (originality). Furthermore, $\mathbf{M}$. was creatively more gifted in the ability to move from one mental category to another one (flexibility) than F.: so, M. used all five categories indicated in the manual almost always alternating them, while F. used four of them often repeating them consecutively. In addition, $\mathbf{M}$. reported higher score in the production of titles than that of F., even if this score is "below average". In detail, F. used the enlarged version provided by the Braille Stamperia of Catania and produced in 17 minutes a single geometric figure, two sidereal objects (sun and star), two living creatures (fish and pedestrians), three commonly used objects (table, handle, drying rack), and three food products (lemon, cake, and provola cheese). F. mentally and graphically represented objects of common use and not simply known forms studied at school. Finally, M. spent 34 minutes (in the first 20 minutes he had executed seven frames, and in 25 minutes eight frames) and made two living beings using the awl (the use of which requires more time than the rapid flow of the pencil on the sheet) (fish and snail), a sidereal object (star), a graphic game (the tic-tac-toc), a submarine, a gift package, a symbol and five 
Table 1. Comparison between scores of participants to the TDT and normative scores.

\begin{tabular}{|c|c|c|c|c|c|}
\hline $\begin{array}{c}\text { Factors of Divergent } \\
\text { Thinking }\end{array}$ & Ss & Gifted & $\begin{array}{l}\text { Above } \\
\text { average }\end{array}$ & Average & $\begin{array}{l}\text { Below } \\
\text { average }\end{array}$ \\
\hline & $\mathrm{N} .=6$ & & & & \\
\hline \multirow[t]{3}{*}{ 1) Fluidity } & F. $=11$ & 12 & 11 & 10 & 8 \\
\hline & M. $=12$ & & & & \\
\hline & $\mathrm{N} .=4$ & & & & \\
\hline \multirow[t]{3}{*}{ 2) Flexibility } & F. $=6$ & 10 & 9 & 7 & 5 \\
\hline & M. $=10$ & & & & \\
\hline & $\mathrm{N} .=4$ & & & & \\
\hline \multirow[t]{3}{*}{ 3) Originality } & F. $=26$ & 32 & 30 & 24 & 20 \\
\hline & M. $=24$ & & & & \\
\hline & N. $=0$ & & & & \\
\hline \multirow[t]{3}{*}{ 4) Elaboration } & F. $=4$ & 27 & 25 & 16 & 12 \\
\hline & M. $=6$ & & & & \\
\hline & N. $=9$ & & & & \\
\hline \multirow[t]{3}{*}{ 5) Production of titles } & F. $=14$ & 36 & 34 & 30 & 29 \\
\hline & M. $=17$ & & & & \\
\hline & N. $=23$ & & & & \\
\hline \multirow[t]{2}{*}{ Total score } & F. $=42$ & 117 & 109 & 87 & 74 \\
\hline & M. $=69$ & & & & \\
\hline
\end{tabular}

graphic products characterized by metaphorical force (cruise; rough sea; rainy day, trip and autumn). It would seem that the highest result is achieved by the currently blind adolescent who used to have the possibility to adopt visual perception in its entirety. The visually impaired adolescent reached lower levels and yet, in any case, higher than those obtained by the blind born boy.

Logical-spatial skills. In relation to the logical-spatial performance, N., born blind boy, completed the colored matrices in 71 minutes with 20 errors; F., the visually impaired boy, using the enlargement provided by Braille Stamperia, completed the matrices in 57 minutes with 14 errors; M., born sighted but currently blind, completed the matrices in 38 minutes and committed only 3 errors. As previously reported, the adolescent who is blind from birth gets the lowest score, while the born sighted and then became blind achieves an excellent result, correctly choosing as many as 33 answers.

We thought necessary to conduct a qualitative analysis related to the typology of errors, as reported by Raven, classifying them into four types. The first one concerns the choice of a completely different and irrelevant fragment with respect to the correct choice (Differences: D.); the second one concerns the Inadequate Identification (I.I.) characterized by the fact that the option chosen combines irrelevant elements, or is contaminated by irrelevant/distorted ele- 
ments or constitutes the whole/half with respect to the matrix to be completed; the third one relates to the Repetition of the Figure (R.F.), where the choice is made on the basis of the adjacent figure to the target on the orthogonal plane; finally, the last error may depend on the Incomplete Correlation (I.C.) described by the fact that the option represents the matrix pattern correctly but not completely. In an Italian research in which the Colored Matrices were administered to Down subjects, the hypothesis that I.C. errors can be considered as a partially adequate response has been advanced, I.I. errors indicate an inadequate response to contamination, R.F. errors a response inadequate for intrusion caused by one dependence on the field/perseverance, D. errors a lack of understanding of the task (Belacchi, Carretti, \& Lanfranchi, 2012: p. 241). The authors note that "the analysis of errors has limits, in fact, for example, not all types of errors are equally possible in the 36 items". Therefore, it is necessary to be very cautious in drawing definitive conclusions from the analysis of the type of errors.

Without going too far into this area, for which we refer to the Italian standardization (Belacchi, Scalisi, Cannoni, \& Cornoldi, 2008), we considered important to reflect on the wrong options. Our results showed that $\mathbf{N}$. correctly identified the first four matrices and the n.6 of the A series, the first three, the n.10 and the $\mathrm{n} .12$ of the $\mathrm{Ab}$ series and the first six of the B series. In detail, in relation to the A series, the four right answers (from n.1 to n.4) depend on the correct identification of the option that contains the identical details present in the matrix. For example, in the n.3 matrix, of the six options provided, three contain the dots present in the matrix, while the other three contain completely different signs (dashes, horizontal, and vertical lines and absence of signs). In the n.5 matrix (not resolved) instead, the options that contain the correct sign are four. N. reported the n.5 answer which indicates the recognition of the correct form but not that of density and size (I.C. error). Among the options of the n.6 matrix (correctly solved), only two contain the horizontal lines that identify the matrix. Probably, the correct identification is made possible only if the search for the solution does not require a high number of comparisons and, therefore, the simultaneous maintenance of multiple mental representations is not required. In the n.7 matrix, N. indicated the n.1 answer (vertical line) with respect to the correct one (n.6) where a vertical intersects with a horizontal one (I.C. error). We find an identical typology of error in the n.8, n.9, and n.10 matrices. The error in the $\mathrm{n} .11$ matrix is of the R.F. type, and in the n.12 matrix the error belongs to the D. type. With reference to the Ab series, the first three answers, which require the identification of the identical option, are correct. In the n.4, n.5, n.6, n.7 and n.9 matrices, the error is the R.F. type (orientation), while in the n. 8 and n.11 matrices the error is the D. type. The response to the $\mathrm{n} .10$ matrix is correct (orientation is respected), as well as for n.12 matrix where $\mathrm{N}$. captured the structural logic. Thus, $\mathbf{N}$. correctly identified the answer to $\mathrm{n} .10$ and $\mathrm{n} .12$ matrices in which the difficulty of identifying the orientation of the figure is present. Beyond the possible randomness that cannot be excluded, carefully observing the n.10 
matrix, we note that the correct answer may have been suggested by the fact that option three is the only one to have a raised outline in the upper side of the square that probably acts as a mental "call" of the square near the missing part in the matrix. The same type of reasoning can also be conducted for the n.12 matrix. In B series, after the $\mathrm{n} .1$ and n.2 matrices characterized by the correct identification of the only option identical to the missing part, the matrices from n.3 to n.6, correctly solved, require an understanding of the orientation. We must ask ourselves why in this series (and not in the previous one) $\mathrm{N}$. has given these correct answers. A possible explanation could concern the fact that in the n.3 matrix, the possible options (for the orientation of the figure in the correct size) are only two, while in the n.4, n.5 and n.6 matrices the solution is facilitated, according to the verbal reasoning produced by the subject, from the identification of the geometrical figure which, in total, is partly obtained. In the matrices from n.7 to n.12, N. always made errors of the R.F. type. Especially the blind adolescent accompanied the execution of the tests with a remarkable verbal elaboration that translated the reflections, the difficulties and the modalities found, from time to time, in the single answers both to the TDT and Colored Matrices. The experimenter transcribed the verbal production of $\mathbf{N}$. In summary, with regard to the performance of the born blind boy (N.), it is possible to note that in nine matrices the options are correctly chosen if the one identical to the one contained in the matrix is identified. The good performance of $\mathbf{N}$. depends on the search for formal identity, made possible by the haptic exploration, carried out using both hands (one on the missing part, the other on the possible choices). The difficulty emerges when the task consists in searching for the form that "completes" the entire matrix, by identifying the lines that make up the overall picture. The representation of the structure as a whole constitutes the way to reach the solution of the problem. With regard to the 20 errors, five can be considered correct but incomplete answers (I.C.), twelve repetitions of figures (R.F.), and three completely different choices (D.).

The detailed analysis of the performance achieved by F., visually impaired from birth, showed that, in the A series, answers are correct from n.1 to n.8 matrices. For these matrices, the correct choice depends on the identification of the option that contains the lines identical to the empty part of the matrix. Instead, F. made errors in the same series, referring to options n.9 to n.12. With respect to the $\mathrm{Ab}$ series, with the exception of $\mathrm{n} .9$ and n.12 matrices, F. correctly identified the answers. Compared to the B series, the correct answers are related to the n.1, n.2, n.4, and n.6 matrices. Analyzing the wrong choices of the A series, we find the presence of two I.C. errors (n.9 and n.10 matrices) and two R.F. errors (n.11 and n.12 matrices). With regard to the Ab series, the errors are both of the R.F. type. In the B series, the errors in n.3, n.5, n.7, n.8, n.9, n.10, n.11, and n.12 are all of the R.F. type. In summary, F. realized two I.C. errors and fourteen R.F. errors. We must take into account the fact that the formal characteristics of the $\mathrm{Ab}$ series mean that the errors are, in a totally prevalent way, of the R.F. type. 
The analysis of the results achieved by $\mathbf{M}$., born sighted and then become blind, indicates a performance far superior to those obtained from the other participants. In fact, the only errors are in the n. 8 matrix of the Ab series and in the n.10 and n.12 matrices of the B series. These errors are all of the R.F. type.

\section{Conclusion}

This study debated the first results of the FIRD Project about the haptic versions of the Test of Divergent Thinking and of the Colored Progressive Matrices for blind and visually impaired participants. The qualitative analysis realized in this paper concerns three subjects similarly characterized by sex, age, schooling, collateral activities, also functional for the recovery of the abilities threatened by the visual impairment. They showed different performances in relation to their visual disability: so, N. was born blind, F. was born and is currently visually impaired, and M., was born sighted but is currently blind. Their performances appear extremely different in relation to several aspects and concern the results achieved in the divergent abilities (explored by means of the TDT) and in the logical-spatial skills (measured by Raven's Colored Matrices). In fact, the number and type of answers provided to the TDT and the Raven matrices seem to indicate the highest level of difficulty in the born blind boy (N.); thus, the answers to the test of divergent thinking, compared with the normative data, showed that the subject is two points "below average" in the quantity of given answers (fluidity), one point "below average" in the ability to pass from a category to another (flexibility), sixteen points "below average" in the ability to execute drawings inside/outside the closed shapes (originality), twelve points "below average" in the ability to not execute symmetrical shapes (elaboration), and twenty points "below average" in the ability to assign metaphorical titles (verbal creativity). Execution inside the closed forms and, therefore, a low level of originality indicates, as reported by Williams (1994: p. 20), the presence of blockage and cognitive rigidity; the symmetry, considered as the characteristic that helps to perceive the gestalt as "good", indicates a sort of rigidity expressed by the presence of a formal identity obtained through the "mirroring". N. is far from producing witty or brilliant titles or which, however, are not limited to expressing slavishly what has been drawn. The low level of creativity (51 points below the average performance) is substantially due to the difficulty in going out mentally from the closed forms, from the bottlenecks of the specular correspondence that appears also in the repetitiveness of the titles. In relation to the Raven matrices the correct answers, added to the I.C. errors (which, as previously noted, can be considered as almost right answers), represent the $58.33 \%$; on the total of the errors (removing those of the I.C. type), the R.F. errors are the $80 \%$ and those D. are the $20 \%$.

With regard to F.'s performance, visually impaired from birth, it is noted that only in two factors and in the total score the subject is positioned in the range below the average; in detail, eight points less in elaboration, fifteen in production 
of titles and twenty-four in total score. Against these levels, however, the ability to move from one category to another (flexibility) reaches a score almost equal to the average expected for his age (one point less) and in originality gets two more points compared to the average score. In fluidity, F. completes 11 frames, almost equal to "the gifted" (12). With respect to the Raven matrices, the correct answers, added to the I.C. errors represent the $66.66 \%$; on the total of the errors (removing those of the I.C. type), the R.F. type errors constitute the $100 \%$.

Even M., currently blind but born sighted, is "below average" in elaboration, production of titles and total performance, but with minor differences compared to $\mathrm{F}$. In fact, with reference to the ability to produce asymmetrical drawings (elaboration), M. places 4 points below average, with respect to the titles eight points below average and in the total the score is three points higher than that indicated as below average. He also scores two points higher than those indicated as "the gifted" in fluidity and flexibility. With regard to the Raven matrices, the percentage of correct answers reaches the $91.6 \%$ while the three errors committed are all of the R.F. type.

\section{Strengths, Limitation and Future Research}

Our study gave an important and unique contribution to understanding of creative abilities and logical-spatial skills of blind and visually impaired adolescents in Italian context using adapted tools for the haptic perception of this selected population in developmental age. It appears clear the need to intervene, at an early age and with systematic methodology also in the scholastic context, using functional strategies and training to strengthen the abilities that, as emerged in our study, seem particularly compromised especially in subjects born blind. We refer to the visual-spatial abilities, which are fundamental for integrating the information coming from the perceptive space, using them and organizing them to perform different tasks, and those proper to divergent thinking, especially in relation to a more metaphorical use of language and a lower adhesion to the rigidity of the symmetry. The main limit of this study is due to the reduced number of participants to this project, chosen among those without other intellectual or genetic disabilities. Future deepening of these findings will concern the two last steps of the FIRD Project, relating to the strengthening of the inadequate divergent skills in blind and visually impaired adolescents by means of specific laboratory activities (third step) and the administering of the parallel form of the TDT (follow up final step) to see if and to what extent the laboratory activities will produce the enhancement of creative abilities. In addition, future investigations with this type of sample with sensorial disabilities will provide for the complete validation of the used measures and the comparison with control group.

\section{Conflicts of Interest}

The authors declare no conflicts of interest regarding the publication of this paper. 


\section{References}

Al-Dababneh, K. A., al-Masadeh, M. M., \& Oliemat, E. M. (2015). The Effect of a Training Program in Creativity on Developing the Creative Abilities among Children with Visual Impairment. Early Child Development and Care, 185, 317-339. https://doi.org/10.1080/03004430.2014.924113

Anderson, R. P. (1961). Modification of the Raven Progressive Matrices for the Blind. Project 670-61-1, U.S. Office of Vocational Rehabilitation.

Belacchi, C., Carretti, B., \& Lanfranchi, S. (2012). Analisi delle prestazioni di individui con la sindrome di Down e con sviluppo tipico nella forma colore delle Matrici Progressive di Raven. Psicologia clinica dello sviluppo, 16, 1.

Belacchi, C., Scalisi, T. G., Cannoni, E., \& Cornoldi, C. (2008). Taratura italiana del test Matrici di Raven Forma Colore (CPM-47). Manuale, Firenze, Giunti Organizzazioni Speciali.

Brambring, M., \& Asbrock, D. (2010). Validity of False Beliefs Tasks in Blind Children. Journal of Autism and Developmental Disorders, 40, 1471-1484. https://doi.org/10.1007/s10803-010-1002-2

De Caroli, M. E. (2009). Pensare, essere, fare ... creativamente. Milano: FrancoAngeli.

De Caroli, M. E., \& Sagone, E. (2010). A Study on Creative Performance in Italian Children with Learning Disability. INFAD-Revista de Psicología, 3, 855-862.

De Caroli, M. E., \& Sagone, E. (2014). Divergent Thinking in Children with Down Syndrome. Procedia-Social and Behavioral Sciences, 141, 875-880. https://doi.org/10.1016/j.sbspro.2014.05.153

De Caroli, M. E., Falanga, R., Licciardello, O., \& Sagone, E. (2017). How Can We Enhance Creativity in Childhood? An Action Research with Italian Children. INFAD-Revista de Psicología, 1, 95-102. https://doi.org/10.17060/ijodaep.2017.n1.v1.902

De Caroli, M. E., Sagone, E., Falanga, R., \& Licciardello, O. (2019). Analysis of Creative and Logical-Spatial Skills in Blind Children and Adolescents. INFAD-Revista de Psicología, 1, 241-249. https://doi.org/10.17060/ijodaep.2019.n1.v1.1416

Eardley, A. F., \& Pring, L. (2007). Spatial Processing, Mental Imagery, and Creativity in Individuals with and without Sight. European Journal of Cognitive Psychology, 19, 37-58. https://doi.org/10.1080/09541440600591965

Green, S., Pring, L., \& Swettenham, J. (2004). An Investigation of First-Order False Belief Understanding of Children with Congenital Profound Visual Impairment. British Journal of Developmental Psychology, 22, 1-17. https://doi.org/10.1348/026151004772901087

Guilford, J. P. (1950). Creativity. American Psychologist, 5, 444-454. https://doi.org/10.1037/h0063487

Guilford, J. P. (1982). Cognitive Psychology's Ambiguities: Some Suggested Remedies. Psychological Review, 89, 48-59. https://doi.org/10.1037/0033-295X.89.1.48

Halpin, G., Halpin, G., \& Torrance, E. P. (1973). Effects of Blindness on Creative Thinking Abilities of Children. Developmental Psychology, 9, 268-274. https://doi.org/10.1037/h0035159

Kirby, M., \& D’Angiulli, A. (2011). From Inclusion to Creativity through Haptic Drawing: Unleashing the "Untouched" in Educational Contexts. The Open Educational Journal, 4, 67-79. https://doi.org/10.2174/1874920801104010067

McAlpine, L. M., \& Moore, C. L. (1995). The Development of Social Understanding in Children with Visual Impairments. Journal of Visual Impairment \& Blindness, 89, 349-358. 
Mednick, S. (1962). The Associative Basis of the Creative Process. Psychological Review, 69, 220-232. https://doi.org/10.1037/h0048850

Millar, S. (1994). Understanding and Representing Space. Oxford: Oxford University Press.

Minter, M., Hobson, R. P., \& Bishop, M. (1998). Congenital Visual Impairment and “Theory of Mind”. British Journal of Developmental Psychology, 16, 183-196. https://doi.org/10.1111/j.2044-835X.1998.tb00918.x

Muniz, M., Gomes, C. M. A., \& Pasian, S. R. (2016). Factor Structure of Raven’s Coloured Progressive Matrices. Psico-USF, Bragança Paulista, 21, 259-272. https://doi.org/10.1590/1413-82712016210204

Occelli, V., Lacey, S., Stephens, C., John, T., \& Sathian, K. (2016). Haptic Object Representation in View-Independent in Early Blind but Not Sighted People. Perception, 45, 337-345. https://doi.org/10.1177/0301006615614489

Pietrini, P., Furey, M. L., Ricciardi, E., Gobbini, M. I., Wu, W. H., Cohen, L., Guazzelli, M., \& Haxby, J. V. (2004). Beyond Sensory Images: Object-Based Representation in the Human Ventral Pathway. Proceedings of the National Academy of Sciences of U.S.A., 101, 5658-5663. https://doi.org/10.1073/pnas.0400707101

Pijnacker, J., Vervloed, M. P. J., \& Steenbergen, B. (2012). Pragmatic Abilities in Children with Congenital Visual Impairment: An Exploration of Non-Literal Language and Advanced Theory of Mind Understanding. Journal of Autism and Developmental Disorders, 42, 2440-2449. https://doi.org/10.1007/s10803-012-1500-5

Raven, J. C., \& Court, J. H. (1998). Raven Manual, Section 1 (General Overview), Section 2 (Coloured Progressive Matrices) and Section 6 (The Crichton Vocabulary Scale). Oxford: Oxford Psychologists Press.

Rich, C. C. (1963). The Validity of an Adaptation of Raven's Progressive Matrices for Use with Blind Children. A Dissertation in Psychology, Lubbock, TX: Graduate Faculty of Texas Technological College.

Runco, M. E. (1991). Divergent Thinking. Norwood, MA: Ablex Publishing Corporation.

Tisdall, W. J., Blackhurst, A. E., \& Marks, C. H. (1971). Divergent Thinking in Blind Children. Journal of Educational Psychology, 62, 468-473.

https://doi.org/10.1037/h0032019

Vanlierde, A., De Volder, A. G., Wanet-Defalque, M. C., \& Veraart, C. (2003). Occipito-Parietal Cortex Activation during Visuo-Spatial Imagery in Early Blind Humans. NeuroImage, 19, 698-709. https://doi.org/10.1016/S1053-8119(03)00153-8

Williams, F. E. (1994). Test della creatività e del pensiero divergente. Trento: Centro Studi Erickson.

Withagen, A., Verloed, M. P. J., Janssen, N. M., Knoors, H., \& Verhoeven, L. (2010). Tactile Functioning in Children Who Are Blind: A Clinical Perspective. Journal of Visual Impairment \& Blindness, 1, 43-54. https://doi.org/10.1177/0145482X1010400108

Wyver, S. R., \& Markham, R. (1999). Divergent Thinking of Children with Severe Visual Impairments. Journal of Visual Impairment and Blindness, 93, 233-236.

https://doi.org/10.1177/0145482X9909300405 